\title{
ANÁLISE GEOGRÁFICA DA RELAÇÃO SOCIOAMBIENTAL EM UNIDADES DE PAISAGEM DA APA CAPIVARI-MONOS NO ANO DE SUA CRIAÇÃO
}

\author{
ANÁLISIS GEOGRÁFICA DE LA RELACIÓN AMBIENTAL EN UNIDADES \\ DE PAISAJE DE LA APA CAPIVARI-MONOS EN EL AÑO DE SU CREACIÓN
}

\section{GEOGRAPHICAL ANALYSIS OF ENVIRONMENTAL RELATIONSHIP IN LANDSCAPE UNITS OF APA CAPIVARI-MONOS IN YEAR OF ITS CREATION}

\author{
Rodrigo Martins dos SANTOS $^{1}$ \\ Leda Velloso BUONFIGLIO² \\ Julio Takahiro HATO ${ }^{3}$ \\ Avelino Los REIS ${ }^{3}$ \\ Tatiana Cyro COSTA ${ }^{4}$
}

RESUMO: Identifica e analisa unidades de paisagem na Área de Proteção Ambiental Municipal Capivari-Monos, extremo sul do município de São Paulo no ano de 2001, época de criação dessa área protegida. Procura contextualizar a atmosfera socioambiental em que a referida unidade de conservação foi criada, cujo objetivo, dentre outros, foi o de proteger uma extensa área rural do município onde há presença da maior densidade de nascentes e cursos d'água que alimentam mananciais de abastecimento da região metropolitana. Analisando as paisagens homogêneas foi possível traçar um diagnóstico perceptivo da realidade socioambiental de cinco localidades, com base na aplicação de questionários e observações diretas. As conclusões são de que há uma discrepância da qualidade ambiental e nível de desenvolvimento social nessas localidades, o que atinge diretamente o bem-estar de quem vive ou depende direta ou indiretamente delas.

Palavras-Chave: Análise Geográfica da Paisagem; Área Protegida; APA Capivari-Monos.

RESUMEN: Identifica y analiza las unidades de paisaje en el Área Municipal de Protección Ambiental Capivari-Monos, extremo sur de la ciudad de São Paulo, en el año 2001, el momento de la creación de esta área protegida. Contextualiza la atmósfera socioambiental en el que la dicha áreas protegidas fue creada, cuyo objetivo, entre otros, era proteger a una amplia zona rural del condado en donde hay presencia de una mayor densidad de manantiales y cursos de agua que alimentan las corrientes de la región metropolitana. Con el

\footnotetext{
${ }^{1}$ Bacharel em geografia pela Universidade de São Paulo (2003), Especialista em geotecnologias aplicadas ao planejamento e gestão ambiental pelo Centro Universitário SENAC (2007), e Mestre em desenvolvimento sustentável com ênfase em povos e terras tradicionais e indígenas pela Universidade de Brasília (2013). geografia@me.com

${ }^{2}$ Bacharel em Geografia (2004) pela Universidade de São Paulo, Mestre em Geografia (2007) pela Universidade de Brasília, doutoranda em Geografia pela Universidade de Campinas. ledabuonfiglio@yahoo.com.br ${ }^{3}$ Arquiteto e Urbanista (1981), Bacharel em Geografia (2007) e Mestre em Geografia Humana (2010) pela Universidade de São Paulo. juliohato@yahoo.com.br

${ }^{3}$ Arquiteto e Urbanista (2000) pela Fundação Armando Álvares Penteado, e bacharelando em Geografia pela Universidade de São Paulo.. avelinolosreis@uol.com.br

${ }^{4}$ Bacharel em Geografia (2005) pela Universidade de São Paulo, Mestre em Governança Ambiental (2012) pela University of Freiburg (Alemanha). geografeiro@yahoo.com.br
} 
análisis de las paisajes homogéneas fue posible establecer un diagnóstico perceptivo de la realidad socioambiental de cinco localidades por medio de cuestionarios y observaciones directas. Las conclusiones son que hay una discrepancia en el nivel de la calidad del medio ambiente y el desarrollo social en estas localidades, lo que afecta directamente el bienestar de aquellos que viven o dependen directa o indirectamente de ellos.

Palavras-Clave: Análisis Geográfica del Paisagem; Área Protegida, APA Capivari-Monos.

ABSTRACT: Identifies and analyzes the landscape units in Capivari-Monos Municipal Ladscap Protection Area, extreme south of City of São Paulo, in the year 2001, the time of creation of this protected area. To contextualize the environmental atmosphere wherein its protected area was created, whose goal, among others, was to protect a large rural area of the county where there is presence of higher density of wellsprings and waterways that feed streams of supply metropolitan region. Analyzing the homogeneous landscapes was possible to draw a perceptive diagnosis of the socio-environmental reality of five localities based on questionnaires and direct observations. The conclusions are that there is a discrepancy in the level of environmental quality and social development in these localities, which directly affects the well-being of those who live or depend directly or indirectly from them.

Keywords: Geographic Landscape Analysis; Protected Area; APA Capivari-Monos.

\section{INTRODUÇÃO}

Este artigo apresenta a análise de unidades de paisagem da Área de Proteção Ambiental (APA) Capivai-Monos no ano de criação desta unidade de conservação de uso sustentável, que foi em 2001.

$\mathrm{O}$ artigo procura responder as seguintes colocações: A compartimentação teórica da realidade facilita a compreensão da paisagem? É possível captar os elementos que a compõe por meio de conceitos da Teoria Geográfica da Paisagem?

Nesse sentido, não deixou de lado a própria problemática da APA: Como uma área considerada única nos termos políticos e legais pôde conter a variedade verificada de unidades e como estes conflitos deveriam ser balizados através do plano de gestão desta unidade de conservação? Qual o disciplinamento capaz de melhorar a vida de seus moradores?

A importância desse registro será relevante para se compreender como era o quadro geográfico dessa área protegida no ano de sua criação. Isto será relevante tanto como um registro histórico como para estudos que necessitem efetuar um comparativo com a situação da referida área em outros momentos. Além disso, serve como aporte às constantes revisões do plano de manejo dessa unidade de conservação. 
O artigo é divido em 3 partes, a primeira trata da metodologia, que se baseia nas escolas da análise da paisagem por meio da percepção ambiental em Del Rio (1999) com aporte da Geografia Cultural em McDowell (1996).

Em seguida há uma contextualização dos fatos que levaram a criação dessa área de proteção ambiental. E por fim, a análise de elementos paisagística da APA com base na metodologia proposta, seguido pela conclusão do texto.

\section{METODOLOGIA}

Visando compreender a paisagem do ponto de vista geográfico, utilizando-se dos conceitos expostos, o artigo promove uma leitura da paisagem delimitada em seus aspectos naturais e culturais. Para tal, adota os seguintes procedimentos metodológicos:

1. Levantamento de documentos base sobre o local: a. Lei Municipal 13.136/2001 que cria a APA Capivari-Monos e legislações correlatas (SNUC - Sistema Nacional de Unidades de Conservação; Legislação Estadual de Proteção dos Mananciais, Constituição Federal, Planos Diretores do Município e da Região Metropolitana); b. Cartas topográficas 1:50.000, geológicas, geomorfológicas e outros temas; c. Fotografias aéreas e imagens de satélite; d. Bibliografias, teses e monografias existentes sobre o tema; e. Entrevistas, aulas e palestras com pesquisadores da temática;

2. Visitas a campo: foram realizadas duas visitas a campo para econhecimento da área, coleta de dados e análise da situação. A primeira nos dias 23 e 24 de setembro de 2001, aos setores norte, sul e oeste da APA, onde foram visitados a aldeia indígena de Tenondé Porã, o bairro de Vargem Grande junto a Cratera de Colônia, o bairro de Engenheiro Marsilac e o Núcleo Curucutu do Parque Estadual da Serra do Mar (PESM) gerido a época pelo Instituto Florestal de São Paulo (IF-SP) no setor sudoeste da área. A segunda nos dias 16 e 17 de novembro de 2001, quando foi visitado o setor leste: Estação Ferroviária de Evangelista de Souza, sítios e áreas de camping ao longo da ferrovia e dos rios Capivari e Monos. Nesta última visita foi também visitada a unidade da FEBEM (Fundação para o Bem-Estar do Menor) em Vargem Grande.

Objetivando a análise da percepção dos usuários locais, foi utilizado métodos variados: as visitas foram documentadas com fotografias e vídeo incluindo entrevistas informais, transcritas ou gravadas junto aos usuários locais (moradores, trabalhadores, turistas etc.) e também entrevistas dirigidas através de questionário, para posterior tabulação e análises. 


\section{O Conceito de Paisagem}

Neste artigo é considerado a paisagem segundo a definição de Bertrand (1971) onde em uma porção perceptível há uma combinação de fatos visíveis e invisíveis que interagem entre si e com sua vizinhança.

Uma unidade de paisagem (UP) seria então um lugar com certa homogeneidade espacial, devido a combinação de caracteres ecológicos e humanos (MONTEIRO, 2000). Ou seja, pela sua composição físico-natural (geologia, clima, relevo, solos, vegetação, fauna...) e antrópica (história, economia, organização social, cultura, mentalidade, costumes...).

A escola metodológica utilizada para captar e entender essa relação natureza-sociedade faz parte da percepção ambiental em Del Rio (1999) com aporte fundamental das teorias da escola de Berkeley sobre Geografia Cultural em McDowell (1996), resumidas a seguir.

\section{Percepção Ambiental}

A percepção ambiental, segundo Del Rio (1999), pode ser entendida como um processo mental de interação do indivíduo com o meio ambiente através de mecanismos de percepção basicamente em dois níveis: 1 . Os primeiros tratam da ação imediata e simples dos estímulos externos captados pelos cinco sentidos (visão, olfato, audição, paladar e tato), onde, geralmente é mais relevante o sentido da visão; 2. Os segundos são os cognitivos, ou seja, aqueles que compreendem, além da primeira percepção, a contribuição da inteligência, na interpretação do ambiente, admitindo-se que a mente não funciona apenas a partir dos sentidos e nem recebe as sensações passivamente.

Esses mecanismos cognitivos incluem motivações, humores, conhecimento prévio, valores, julgamentos e expectativas, fazendo com que a mente organize e represente a realidade através de esquemas perceptivos e imagens mentais com atributos específicos (DEL RIO, op. cit.).

Neste estudo de caso, em virtude da complexidade natural e cultural em que está inserida a APA Capivari-Monos, tornou-se evidente a necessidade de se questior quais seriam as percepções dos diversos usuários em seus relacionamentos com o meio ambiente e entre si, ou entre as comunidades.

Para isto, foi elaborado questionário de campo onde os entrevistados respondem às questões no primeiro nível, apenas sensitivo de identificação com o seu lugar e num segundo nível respondem de maneira cognitiva julgando e avaliando os diversos elementos que compõem sua realidade ou paisagem. Isto permitiu uma avaliação das expectativas e da 
imagem mental das diversas comunidades e usuários em relação à criação da APA CapivariMonos, e assim subsidiar uma verificação em relação ao plano de manejo constante em Bellenzani (2011), para verificar se este está contemplando as expectativas da população e os objetivos e diretrizes da APA, ou se os usuários estão conscientes de sua criação.

A metodologia na qual se baseou o estudo da percepção, além das escolas mais tradicionais e consagradas de análise da paisagem como Bertrand (1977) e Monteiro (2000), considerou a discussão no âmbito da Geografia Cultural em McDowell (1996). A escola de Berkeley, década de 1920, introduz a problemática através da própria discussão de cultura, considerando que a paisagem seria o resultado direto das práticas culturais de determinada sociedade, devendo ser considerada o ponto central da análise geográfica. Refutada no pósguerra, é submetida a uma reteorização pela escola do paisagismo. As principais críticas referiam-se a seu caráter apolítico que não considerava as relações de força e poder que configuram o espaço. Ademais, passa também a ser considerada como produto da percepção:

Os novos geógrafos reteorizaram a paisagem não apenas como o resultado material de interações entre o ambiente e a sociedade, mas também como consequência de uma maneira específica de olhar (McDOWELL, 1996: 176).

Os conceitos desta discussão foram incluídos nas reflexão sobre a APA principalmente nas análises referentes à percepção ambiental. A seguir, na Fig. 1, um resumo do esquema utilizado nas análises.

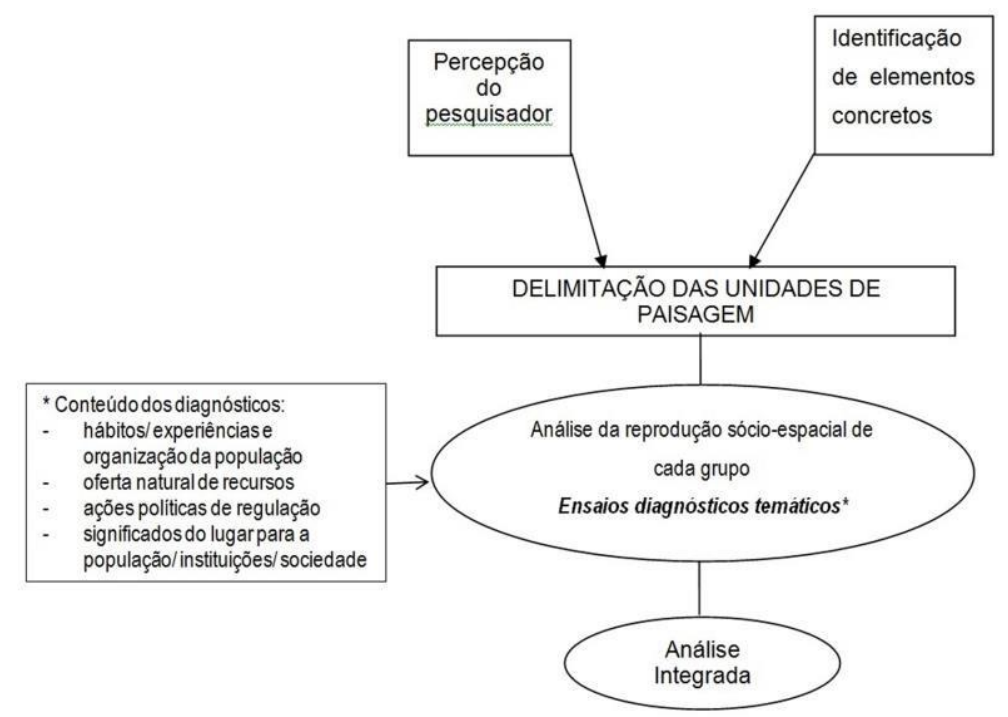

Fig. 1. Modelo de análise da paisagem sob o prisma da escola da percepção ambiental. Org. os autores. 


\section{CONTEXTUALIZAÇÃO SOCIOAMBIENTAL DA CRIAÇÃO DA APA}

A APA do Capivari-Monos, criada pela Lei no 13.136/2001, localiza-se no extremo sul do Município de São Paulo. Possui uma extensão territorial de $251 \mathrm{~km}^{2}$, abrangendo aproximadamente um sexto do território do Município, compreendendo parte das bacias hidrográficas do Guarapiranga; Billings; e Capivari-Monos e está totalmente inserida na área de proteção aos mananciais (BELLENZANI, 2000).

A APA limita-se a sul com os municípios de Itanhaém e São Vicente; a leste com São Bernardo do Campo; a norte com as margens da represa Billings (até o braço Taquacetuba); contorna os limites norte e oeste da Cratera de Colônia; a nordeste no divisor de águas do Ribeirão Vermelho; e a oeste com os municípios de Embú-Guaçú e Juquitiba.

O acesso principal se dá pelo Município de São Paulo, via estrada de Parelheiros (atual Av. Sadamu Inoue), de onde se segue pela estrada de Colônia, ou pela estrada de Engenheiro Marsilac. Outros acessos possíveis são via São Bernardo do Campo, pela rod. dos Imigrantes e via Embu-Guaçu, pelo bairro do Cipó (SÃO PAULO (município), 2001a).

Insere-se na Reserva da Biosfera do Cinturão Verde da cidade de São Paulo e concentra os últimos remanescentes da Mata Atlântica do Município. Um aspecto importante é a presença de unidades de conservação e áreas correlatas situadas no perímetro da APA. São elas: Núcleo Curucutu do Parque Estadual da Serra do Mar; Área Natural Tombada da Cratera de Colônia; Área Natural Tombada da Serra do Mar; e Reservas Indígenas.

Nela encontra-se diversos elementos paisagísticos notáveis, como: aldeias indígenas da etnia Guarani (Tenondé Porã, Krucutu e parte da Rio Branco); a Cratera de Colônia, obra do choque de um meteoro com a Terra no final do período Cretáceo (65 milhões de anos), e que hoje abriga um gigantesco bairro irregular, o Vargem Grande; os bairros tradicionais de Colônia, Embura (Gramado) e Eng. ${ }^{\circ}$ Marsilac, os primeiros fundados por imigrantes alemães vindos ao Brasil na primeira metade do século XIX, e o último, apesar de ter recebido pequeno contingente dessa leva de imigrantes, foi fundado mais recentemente, cerca de cem anos depois, tendo surgido junto com a construção do ramal Santos-Mairinque da antiga Estrada de Ferro Sorocabana - E.F.S., e recebeu o nome do engenheiro responsável pela obra. 
Além destes elementos citados, há na área em estudo outros não menos relevantes, e que apresentam juntos a maior extensão de Mata Atlântica preservada do município, são eles: o Núcleo Curucutu do Parque Estadual da Serra do Mar, ponto limítrofe com o município de Itanhaém; e a região de Evangelista de Souza, que possui em sua paisagem instalações ferroviárias da antiga Estrada de Ferro Sorocabana (EFS), uma enorme cachoeira, o entroncamento dos rios Capivari e Monos e diversos sítios rurais tradicionais.

\section{Cobertura, uso e ocupação do solo}

Para a criação da APA Capivari-Monos a Secretaria Municipal do Verde e do Meio Ambiente (SVMA) realizou um mapeamento do uso e ocupação do solo. A maior parte (73 \%) era coberta por vegetação nativa de Mata Atlântica, cujos remanescentes mais expressivos localizavam-se na bacia hidrográfica do Capivari-Monos, um indicador de que se tratava de uma área bastante conservada, especialmente no contexto do Município de São Paulo. Das categorias de vegetação, as florestas secundárias representam a classe mais significativa. Considerando o banco de sementes existente, tais matas, se manejadas adequadamente, podem avançar no processo de sucessão vegetal. As matas mais preservadas estão no vale do rio Capivari, em locais de difícil acesso (BELLENZANI, 2000). O plano de manejo da unidade indicou um acréscimo de 4\% da cobertura vegetal no ano de 2008, atingindo 77\% da área total da unidade (BELLENZANI, 2011: 135).

A diversidade de ambientes existentes na região proporciona uma variada oferta de habitats disponíveis e consequentemente de animais a estes relacionados. Segundo relatório de impacto ambiental elaborado pela Eletropaulo (1995), nas bacias dos rios Capivari e Monos foram encontrados vestígios dos seguintes mamíferos: anta, irara, caxinguelê, sagui, capivara, paca, cutia, ouriço e preá, além da ocorrência da onça parda. Em 2010 o plano de manejo da unidade revelou a ocorrência de 364 espécies de vertebrados na região (BELLENZANI, 2011: 74).

As áreas sem cobertura nativa (23\%) são caracterizadas por um mosaico de ocupações rurais e agrícolas (9\%), entremeadas por áreas de reflorestamento (especialmente Pinus) e chácaras de recreio (10\%), destinadas à segunda residência, sendo que muitas delas vêm sendo atualmente alugadas para festas e/ou transformadas em empreendimentos voltados ao turismo/educação ambiental, ainda que de forma espontânea e precária. Loteamentos (4 \%) são mais presentes na bacia da Billings e na região conhecida por Barragem, limite das bacias Capivai-Monos e Billings. Os maiores loteamentos irregulares são o denominado 
Condomínio Vargem Grande e o bairro Cidade Nova América. São áreas precariamente urbanizadas e carentes de serviços públicos. (BELLENZANI, 2000; 2011).

A agricultura, atividade que já foi expressiva na região, está desaparecendo. Tanto o reflorestamento como a mineração, também estão em declínio e empregam pouca mãodeobra. A população carece de oportunidades de emprego e renda, quadro que tem sido agravado com o adensamento dos núcleos populacionais existentes, onde é crescente a violência decorrente da situação de exclusão social.

A manutenção e dinamização das atividades econômicas compatíveis com a proteção do meio ambiente, o ecoturismo, o turismo rural, os serviços de lazer, agricultura orgânica, apicultura, viveiros de espécies nativas etc., são alternativas capazes de minimizar a expansão urbana e gerar renda e melhoria da qualidade de vida para a população local.

Esta região está inserida nos distritos censitários de Parelheiros e de Marsilac. Segundo o Mapa da Exclusão/Inclusão Social do Município de São Paulo, estes distritos estão entre os mais problemáticos. Enquanto a média de crescimento populacional da cidade de São Paulo entre 1991 e 1996 foi de 0,40 \%, os distritos de Parelheiros e Marsilac apresentaram, respectivamente, 8,2 \% e 4,5\% (SPOSATI, 1996). No período de 1996 a 2002 essa taxa ficou em 0,8 \% para a cidade, e $5 \%$ para Parelheiros e 3,5\% para Marsilac (SÃO PAULO (município), 2006). Essa alta taxa de crescimento torna-se um sério problema ambiental por ser uma região de Área de Proteção aos Mananciais e tem efeitos sociais perversos. Os dados coletados mostram que o crescimento demográfico não foi acompanhado da melhoria da infraestrutura, nem sanitária nem de serviços, criando verdadeiros bolsões de miséria, caracterizada por indicadores como acesso precário aos serviços públicos de educação e saúde, infraestrutura sanitária inadequada, baixa escolaridade, renda média por família abaixo de 2 salários mínimos (Marsilac), e oferta de emprego muito aquém do necessário.

Apesar do crescimento demográfico, a região ainda mantém suas características rurais, e a maior densidade de nascentes e curso decágua da cidade de São Paulo, sendo que a urbanização é dispersa em alguns pontos.

\section{Histórico da ocupação}

Os primeiros moradores da região foram os indígenas. Os Guarani - grupo indígena que povoou a região por diversas épocas distintas - deixaram a região da Serra do Mar ainda 
no século XVI - coincidentemente na época da colonização portuguesa no planalto - e partiram em direção ao atual Paraguay (BARBOSA, 1994).

Durante o período que compreende a saída dos Guarani (séc. XVI) e o início da imigração europeia promovida pela império (séc. XIX), pouco se tem de informação. Porém sabe-se que nenhuma vila, vilarejo ou povoado, foi fundado na região durante esse período, tendo se mantida como terras devolutas sob o território da vila de Santo Amaro.

Na primeira metade do século XIX, sob ordens do Imperador D. Pedro I, deram início os processos de "branqueamento do povo brasileiro", e assim, chegam ao Brasil as primeiras levas de imigrantes europeus advindos da Alemanha. Dos quase mil colonos que chegaram em São Paulo, um terço ficou na região de Penha e Guarulhos, outro terço ficou na região de Cipó (vila de Itapecerica da Serra) e os outros ficaram na vila de Santo Amaro, na região de Colônia e Gramado, ambas situadas nos limites da APA (R. SANTOS, 2005).

Após as fixações desses alemães, a região adquire um caráter estritamente rural, e no final do século XIX já apresenta diversos povoados como o de Santa Cruz dos Parelheiros, Embú-Guaçú e a vila de São José, todos eles sob alguma influência das famílias descendentes dos colonos alemães. Isso é evidente nos sobrenomes presentes em alguns logradouros centrais dessas regiões, como Boemer, Roschel, Schunck, Oberhuber, Guilguer, Reinberg, etc. Ainda no século XIX, os Guarani, retornam a região da Serra do Mar, buscando a "Terra Sem Mal", e fundam a Aldeia do Rio Branco, às margens do rio de mesmo nome, e que tem como principal afluente o rio Capivari, que desce a Escarpa vindo de Evangelista de Souza (AZANHA \& LADEIRA, 1988).

Na primeira metade do século XX chega à São Paulo algumas levas de imigrantes japoneses, que fixam residência nas áreas que circundam a cidade de São Paulo, dentre elas a zona rural do novíssimo bairro de Santo Amaro, anexado a capital paulista, e alguns deles fixaram residência na região da APA (R. SANTOS, 2005).

Também é nesta época que se efetua a construção da ligação portuária da antiga EFS, que tem incluso em seu projeto a construção da estação de Evangelista de Souza e da parada de Engenheiro Marsilac.

Os Guarani, continuando sua busca religiosa, já utilizavam os cursos dos rios Capivari e Monos como caminho em direção à Parelheiros, Santo Amaro e Jabaquara, onde realizavam o comércio de seus artesanatos e produtos da floresta (como os palmitos), e também onde obtinham alguns produtos industrializados, como roupas (CHEROBIM, 1986). 
Este percurso fez surgir, em meados da década de 1960, às margens da represa Billings, as aldeias de Krucutu e Morro da Saudade (atual Tenondé Porã), esta mais conhecida como

„Aldeia da Barragem“e, devido à existência de uma barragem construída pela companhia energética que administrava a represa, e que serviu de ponto de referência para a região, dando nome inclusive ao bairro mais próximo, o Barragem (BARBOSA, 1994).

\section{Retratos do passado: a região periférica da cidade de São Paulo}

A partir do agigantamento da metrópole, em meados da década de 30, delineou-se com mais clareza o intenso contraste entre o centro urbano e as áreas periféricas da cidade de São Paulo. São inúmeras as obras que tratam deste tema, mas o objetivo deste artigo é menos o de acompanhar esta gênese do que captar os principais signos que compunham estas paisagens.

De caráter eminentemente rural, toda área circunvizinha à cidade permanecia em estado de pobreza, na ausência de equipamentos urbanos e infraestrutura básica. Não havendo interesse em sua valorização, o sistema de comunicação viário, com seus modestos caminhos vicinais, permaneceu não desenvolvido, favorecendo o isolamento (BRUNO, 1967). Por sua vez, o solo já muito desgastado pelas roças para subsistência da população, junto ao clima, não eram propícios à configuração de um cinturão agrícola para abastecer a cidade.

Durante um século, caipiras marcaram a paisagem cultural dos arredores de São Paulo, seus contatos com a metrópole sendo feitos à custa de uma atividade comercial modesta: utilizando cargueiros isolados, tropas pequenas, ou carros de boi, levavam suas mercadorias para a cidade (PETRONE, 1995).

Assim, definiam-se claramente duas paisagens: uma já plena de signos urbanos e outra às margens deste processo, com áreas de isolamento até bem recentes, como é o caso do "sertão" de Santo Amaro, que inclui os bairros de Parelheiros, Bororé, Marsilac, e toda área recoberta pela APA Capivari Monos. Com o impactante e explosivo processo de crescimento da cidade, que se acelera a partir da década de 1970, este cenário começa a ser transfigurado.

O mundo caipira dos arredores de São Paulo praticamente já está se tronando um fato do passado. (...) O cinturão caipira, inclusive os seus sertões, tornou-se rápido área pioneira do espaço urbano paulistano. (...) Tornou-se um cinturão de especulação imobiliária, o loteamento sendo o seu principal negócio (PETRONE, 1995: 378). 
O urbano passa a englobar esta imensa área abandonada à sua sorte até então, e o conflito entre os modos de vida vai gerando situações e paisagens particulares, dependendo do modo pelo qual as mudanças são assimiladas (SEABRA \& SPÖRL, 1997). Nas áreas do entorno imediato do grande centro metropolitano, a que manteve mais sinais de isolamento:

\begin{abstract}
Modificaram-se as paisagens culturais. O caminhão e o automóvel substituíram cargueiros e carros de boi; velhos e modorrentos núcleos tornaram-se centro de desenvolvimento próprios a um subúrbio (...); o caipira tornou-se sempre mais raro, submerso pela massa da população cosmopolita que do aglomerado transbordou para todas direções; recuou quando possível, buscando uma sobrevivência de si e de seu modo de vida nos ângulos mais isolados. Porém, estes começaram a ser devassados pela expansão da metrópole, e os próprios sertões foram violados. O sertão de Santo Amaro é atualmente uma das frentes mais vivas da expansão do espaço urbano, que se esgueira pelas áreas deixadas livres pelas águas das represas (PETRONE, 1995: 378).
\end{abstract}

Apesar deste aspecto, a região não pode mais ser caracterizada em sua homogeneidade, já que o urbano, atua em diferentes graus de pressão nesta paisagem, dependendo de fatores como a distância ou potencialidades variadas, conforme os interesses econômicos que engendram o processo da urbanização periférica.

O insustentável avanço da mancha urbana paulistana para os mananciais sul

O crescimento demográfico da cidade e suas proporções espaciais e socioeconômicas atingem taxas preocupantes, pois além de ultrapassarem as expectativas projetadas encontram um contexto urbano totalmente despreparado para isto.

Surge um novo momento na realidade espacial da cidade representado pela expansão urbana para todas as direções, sobretudo rumo ao sul com o acesso facilitado pelas vias marginais Tietê e Pinheiros que vieram após a retificação do curso do Rio Pinheiros, a construção da barragem e a operação de bombeamento do rio em sentido contrário pela Companhia Light and Power (SEABRA \& SPÖRL, 1997).

$\mathrm{O}$ crescimento acelerado da metrópole fez a macha urbana se estender em áreas inadequadas à ocupação, de risco geotécnico ou de interesse ambiental. Vastos terrenos antes utilizados para agricultura e outros usos rurais foram loteados de forma rápida e sem planejamento, e muitos parcelamentos foram aprovados por órgãos de competências diversas sem algum projeto. $\mathrm{O}$ panorama desta ocupação foi tornando-se mais critico com o passar dos anos e poucos instrumentos legais criados para o controle desta, se efetivaram na prática. 
O espaço urbano ou o tecido urbano ${ }^{5}$ em grandes cidades contemporâneas se apresenta heterogêneo, marcado por fortes contradições sociais a partir do momento em que o próprio espaço se torna mercadoria. O resultado disso será uma valorização desigual do espaço urbano, pois ssegundo Lefebvre (1976) “a violenta dispersão das antigas urbes suscita segregações multiformes; os elementos da sociedade tornam-se inexoravelmente separados uns dos outros no espaço"6 (p. 67, traduzido pelos autores).

Entre os anos de 1980 e 1997, um mercado de terras incrustado na ilegalidade das ocupações e na informalidade das habitações criou um contexto marcante na paisagem local. Autoconstrução de loteamentos precários e clandestinos se proliferaram, surgindo como alternativa para grande parte da população (MARCONDES, 1999).

Como escreve Ermínia Maricato (1995), a ilegalidade na condição de moradia (favela, loteamento ilegal ou aluguel informal de cômodo) bem como a ilegalidade de outras condições e relações (legalidade generalizada) é uma das faces mais centrais da exclusão, “exclusão que é política: negação da cidadania" (p. 169), pois:

nas áreas de exclusão social, o Estado se apresenta ausente, ambíguo e arbitrário (quando interessa, a justiça pode ser acionada e a favela removida. Durante o período eleitoral, ao contrário, algumas simples benfeitorias podem trazer votos e consolidar a favela) (p. 168).

O sucesso do processo foi tão grande que envolveu setores políticos, municipais e estaduais, administrativos, privados e até policiais em um esquema de corrupção e violência intensa que durou muitos anos. São gerações que nasceram em bairros com esta origem.

As relações de produção existentes foram se estendendo, e conquistando amplamente mais espaços. Os limites entre o rural e o urbano, antes bem definidos, a partir de então, começam a se confundir, configurando-se em limites móveis e incertos.

A partir da expansão urbana descontrolada e valorização desigual do espaço urbano, surge a grande periferia nas áreas marginais da cidade, é o fenômeno da "expansão urbana periférica" ou "periferização".

A obscuridade do processo se tornou em hábito e tradição locais, um verdadeiro mercado alternativo da tão sonhada casa própria enraíza-se na região sul, principalmente nas bacias da Guarapiranga, Billings e Pirajussara; há uma autofagia da cidade legal e planejada sob a omissão de seus governantes (MARCONDES, 1999).

\footnotetext{
${ }^{5}$ Conceito usado por Milton Santos.

6 “La violenta dispersión de las antiguas urbes suscita segregaciones multiformes; los elementos de la sociedad quedan inexorablemente separados unos de los otros en el espacio"(LEFEBVRE, 1976: 67).
} 
A indefinição dos limites fundiários do patrimônio coletivo possibilitou a lenta privatização dos recursos naturais, dando os contornos e espelhando e relação entre a cidade e os recursos naturais neste contexto, longe de preocupações sociais com o problema habitacional grave da metrópole, os mecanismos de defesa do Estado articularam um apressado processo para reverter a indisponibilidade de controle dos recursos naturais, surge então as Leis da Área de Proteção e Recuperação dos Mananciais (APRM) - Leis Estaduais 898/75, $1172 / 76$ e 9.866/97.

A partir da criação dessa Lei em 1975, ao invés de proteger as regiões de mananciais do uso desordenado do solo, ocorreu o inverso, os índices de crescimento populacional nas áreas das bacias hidrográficas das represas Billings e Guarapiranga era um dos maiores da RMSP, pois a partir desta Lei o valor do solo ficou muito reduzido, embora tenha sido condicionado o uso, porém, devido a precária fiscalização, a atuação de especuladores e fraudadores foi muito facilitada (SEABRA \& SPÖRL, 1997).

A Zona Sul do município de São Paulo foi a região que mais se "favelizou" nas últimas três décadas e aproximadamente metade dessas favelas estão às margens dos reservatórios. E esta parte da cidade, abriga a maior porção paulistana da APRM de Interesse Metropolitano do Estado de São Paulo, onde se encontram parte das bacias hidrográficas das Represas Billings e Guarapiranga, e toda a área da bacia hidrográfica dos rios Capivari e Monos, utilizadas para abastecimento pelo estado. As Leis da APRM no entanto de pouco serviram para conter o uso desordenado do solo na porção sul da Região Metropolitana, especialmente nas áreas mais próximas das represas (SÃO PAULO (estado), 1997). Os principais motivos que tornaram a Zona Sul do Município como uma das áreas mais criticas neste processo são os seguintes: 1 - grande estoque de terra. Trata-se de uma área com tradição na atividade rural, e é o antigo município de Santo Amaro; 2 - proximidade aos polos industriais metropolitanos, ABC e o Distrito Industrial de Santo Amaro e Capela do Socorro; 3 - a rede de transportes implantada condicionou e consolidou o acesso ao centro de São Paulo e a estes distritos, primeiramente pela estrada de ferro, depois pela construção da malha viária e dos corredores de ônibus; 4 - falta de políticas habitacionais nas áreas mais centrais, esta que é apontada como uma das maiores causas da ocupação acelerada na região; 5 - com referencia ao item 4, o processo de "desfavelização" e a imediata desocupação de habitações irregulares na área do "centro expandido" literalmente "varreu" um grande contingente populacional para esta região, sem planejamento algum; 6 o isolamento 
administrativo, dentro do sistema administrativo municipal, que transformou a região em reduto da ilegalidade.

Na década de 1990 o estado era alarmante, a proliferação de loteamentos irregulares na direção sul já havia invadido, inclusive, áreas tombadas como patrimônio natural e seu controle já estava mais do que urgente.

Devido a essa falta de controle pelo Estado no direcionamento do uso do solo nas áreas de mananciais, a Prefeitura do Município de São Paulo resolveu criar no extremo meridional de sua jurisdição, na área com maiores níveis de preservação ambiental, e portanto, com melhores condições de controle, a APA Capivari-Monos, com o intuito de proteger com eficácia algumas cabeceiras e cursos deágua relevantes para a região, além de promover atividades de educação e integração cultural/ambiental para as comunidades locais e para sociedade em geral.

Foi então que se iniciou em 1996 o processo de criação da APA Capivari-Monos, graças às iniciativas de alguns fiscais, lideranças de bairro, entidades não governamentais, e outros que atuavam na região, em especial Maria Lúcia Ramos Bellenzani, na época fiscal municipal nas áreas de mananciais e que foi uma das principais motivadoras e mentoras do projeto, chegando a defender uma dissertação de mestrado sobre a importância de se implantar uma

APA no local e liderar a equipe de planejamento da SVMA, designada a efetivar o projeto (cf.BELLENZANI, 2000).

\section{ANÁLISE DAS UNIDADES DE PAISAGEM NA APA CAPIVARI-MONOS}

A pesquisa de campo foi realizada por meio da aplicação de questionários a moradores e visitantes em unidades de paisagem definidas como homogêneas para esta pesquisa. Foram cinco as localidades definidas assim, a saber: Cratera de Colônia - Vargem Grande; Estação Ferroviária de Evangelista de Souza; Núcleo Curucutu do Parque Estadual da Serra do Mar; Vila de Eng. ${ }^{\circ}$ Marcilac; Aldeia Guarani Tenondé Porã. A seguir as constatações nessas UPs.

\section{Cratera de Colônia - Loteamento Vargem Grande}

Na cratera de Colônia, surge o Vargem Grande...

A produção e a reprodução do espaço urbano se materializam a partir dos processos de execução do ambiente construído, tendo como um dos seus principais elementos a moradia (VICTORINO, 1996). 
Trata-se de uma complexa paisagem criada tanto por peculiaridades naturais - cratera testemunha de um fenômeno astronômico, possivelmente resultado do impacto de um meteoro - como pelas peculiaridades humanas.

Esta paisagem reúne em si aspectos distintos por ser ao mesmo tempo local de moradia precária para aproximadamente 25.000 pessoas em $2000^{7}$, encontro de remanescente de Mata Atlântica e campo de Várzea, e sítio onde há instalada uma Unidade da FEBEM (antes um antigo presídio estadual).

Além disso é ao mesmo tempo um sítio arqueológico de interesse cultural e histórico, tombada em 1996 pelo Condephaat (Conselho de Defesa do Patrimônio Histórico, Arqueológico, Artístico e Turístico do Estado de S. P.) e pelo Compresp (Conselho Municipal de Preservação do Patrimônio Histórico, Cultural e Ambiental da Cidade de S. Paulo).

A situação geomorfológica peculiar da Cratera, circundada externamente por colinas recobertas por vegetação de grande porte, condiciona um microclima e drenagem particular. O principal rio, o Ribeirão Vermelho à jusante da várzea, deságua atualmente no Braço Taquacetuba da Billings, cuja importância é incontestável para a Região da Grande São Paulo. A várzea do Ribeirão Vermelho, expressiva área dentro da Cratera, possui uma vegetação típica de locais brejosos. Ela tem a importante função depuradora protegendo recursos hídricos que abastecem a RMSP. A parte recoberta pela Mata Atlântica possui altíssima diversidade de epífetas com espécies endêmicas inclusive e apresenta solo turfoso (BELLENZANI, 2000).

A maior parte da população da Cratera vive no loteamento chamado Condomínio Vargem Grande. Ainda dentro da Cratera, existem algumas propriedades rurais com diversas atividades. Órgãos ambientais preocupados com a degradação dos aspectos naturais da Cratera, propuseram a criação de um Parque Natural Municipal de 150 hectares em seu interior com o objetivo de conter a expansão do loteamento, criado pelo Decreto Municipal n. ${ }^{\circ} 48.423$, de 11 Jun. 2007.

O Vargem Gde conta com duas escolas (uma Municipal outra Estadual), ponto de ônibus terminal (de onde chegam ônibus de quase toda a região sul da cidade) e um posto policial. Entre as necessidades de infraestrutura reclamam iluminação, esgoto e posto médico.

\footnotetext{
${ }^{7}$ Para 2010 o plano de manejo da APA indicou um acréscimo de 44\% da população nesse setor em relação a 2000 (BELLENZANI, 2011: 99), ou seja, cerca de 36.000 hab. em Vargem Grande.
} 
Mais do que pela dimensão do loteamento, a singularidade está em sua organização e processo de ocupação, já que este, diferentemente da maior parte dos loteamentos da região na mesma época, foi construído depois do direito de terra adquirido, ou seja, eles ocuparam após compra da terra.

\section{Origem do loteamento}

De acordo com Victorino (1996) o processo de assentamento teve seu início em março de 1989 a partir da organização União das Favelas do Grajaú (UNIFAG) que adquiriu uma gleba de $2.932 .000 \mathrm{~m}^{2}$ na Cratera através de transação imobiliária comum.

A entidade civil UNIFAG, presidida então por Maria Sipriana Henrique, conseguiu organizar em torno de 3.500 associados em um único ano. Em sete anos, assentou mais de 10.000 pessoas. As pessoas interessadas em comprar os lotes de $250 \mathrm{~m}^{2}$, preencheram fichas de inscrição e pagaram em agência bancária duas prestações sem exigência como previa os Estatutos. Vale destacar que a Lei de Proteção aos Mananciais não permitia a comercialização de lotes inferiores a $500 \mathrm{~m}^{2}$ (ibid.).

Atualmente, o assentamento está sob a diretoria do Associação dos Moradores de Vargem Grande (ACHAVE) que obteve vitória na eleição de 1996. Além do presidente, são eleitos 12 diretores para gestão de 4 anos.

O assentamento Vargem Grande fixado no interior da Cratera, é analisado com uma série de reprovações do ponto de vista ambiental e mesmo de saneamento básico. Uma área de várzea não aconselhável ao assentamento devido à proximidade com o lençol freático. De acordo com um morador entrevistado - e que não quis se identificar - o número de lotes em 2001 girava em torno de 5.580, em situação precária, sem rigores técnicos, ausência de canalização de esgoto o que faz com que os moradores lancem o lixo em calhas que seguem para o Ribeirão Vermelho, que desemboca em um dos braços da represa Billings. São recorrentes as enchentes durante os verões (dezembro a março) que alagam e destroem dezenas de lotes ocupados.

Sobre as limitações da vida cotidiana dos moradores do Vargem Grande, foi possível verificar sérios problemas explicitados sobretudo pelas crianças e adolescentes entrevistados.

O Vargem Grande, entre outros tantos loteamentos em São Paulo, é fruto do processo de expansão urbana periférica (conforme abordado no presente artigo): a pressão urbana sobre zona com característica rural somada a ausência de política habitacional, resultou em 
um movimento popular urbano que se organizou para ocupar áreas rurais, mesmo que irregularmente, pois o objetivo principal era a conquista da moradia.

Reflexão sobre esta unidade de paisagem

Uma pessoa que não esteja familiarizada com a periferia urbana brasileira se espantaria ante a vista panorâmica da Cratera, do alto da estrada da Febem. V. Grande é um longínquo ponto na urbe de São Paulo, sendo poucos os paulistanos que o conhecem.

Seja pela ausência do Sol, encoberto pela atmosfera quase sempre nublada, seja pelo quase desprezo da sociedade paulistana em geral - que se diz ecológica e tolerante - é pouca a luz que se lança sobre o Vargem Grande.

Nota-se visivelmente que há uma certa homogeneidade que credencia o Vargem Grande como uma unidade de paisagem, diferenciando-se das demais da APA, de acordo com a metodologia aqui apresentada. Suas casas autoconstruídas, nascidas velhas, já feitas ruínas, ruas de terra, a precariedade dos elementos que se destacam na paisagem.

O que se vê, se sente, como a umidade na pele; se ouve, como as risadas dos moleques em sua interação conosco, pessoas de fora, e músicas populares tocadas alto em volume no terminal de ônibus (também ponto de encontro da população local), as escadas que sobem às lajes dos lotes, seus lares.

É possível perceber também as relações pessoais com o ambiente local, os conflitos e as expectativas locais mais explícitas nas crianças e adolescentes.

\section{Estação ferroviária de Evangelista de Souza}

A região de Evangelista de Souza possui este nome devido a existência de uma estação ferroviária com o mesmo nome. Esta é a região mais preservada da APA, e também é a que possui as mais formidáveis belezas naturais e históricas.

\section{Patrimônio Histórico}

A estação ferroviária da antiga Estrada de Ferro Sorocabana (EFS), construída na década de 1940 para servir de entreposto entre o litoral e o planalto paulista, possui uma área de aproximadamente $4 \mathrm{~km}$ de extensão por $500 \mathrm{~m}$ de largura, na qual está incluso a área do pátio de manobras, vila ferroviária e entroncamento (SÃO PAULO (município), 2001b).

É nesta estação que encontra-se o entroncamento dos ramais Santos-Mairinque e SantosOsasco. O primeiro partindo da região de Sorocaba, cruzando São Roque, Rodovia Régis Bitencurt, Itapecerica da Serra, Embú-Guaçú, Cipó e Marsilac. Após sua construção - 
meados da década de 1930 - serviu como principal ligação do porto ao interior paulista, principalmente para o escoamento do café. O segundo ramal - Santos-Osasco - é mais recente por volta da década de 1950. Em 2001, no ano de criação da APA Capivari-Monos, ele passava pelas zonas sul e oeste da capital paulista, margeando os rios Jurubatuba e Pinheiros. Em Santo Amaro circunda a região da Barragem de Pedreira, e o extremo sul da cidade pelas regiões de Cidade Dutra, Grajaú e Parelheiros. Atualmente o trecho entre o Grajaú e Evangelista de Souza está abandonado, e os trilhos foram retirados.

Na década de 1970 todo o complexo da EFS passou a ser propriedade da jovem estatal Ferrovias Paulistas S/A (FEPASA), privatizada em 1998 em favor da Ferroban (Ferrovias Bandeirantes S.A.) adquirida pela ALL (América Latina Logística) em 2006. A estrada de ferro, construída entre as décadas de 1920 e 1930, possui um enorme patrimônio histórico.

Ademais da estação de "Evangelista" - como é conhecida a região - existem belos túneis, estações serranas e altíssimas pontes; além de uma antiga usina hidrelétrica localizada na Cachoeira do Capivari.

\section{Patrimônio Natural}

Em 2001, próximo a estação encontrava-se alguns sítios cobertos por vegetação não nativa, principalmente de pinheiros e eucalíptos, que foram plantados, segundo um morador antigo, a partir da década de 1960, e eram utilizados, em grande parte, pela companhia de trens na confecção de dormentes da linha. Também era extraído a seiva da árvore para usos industriais. A partir do final da década de 1980, com a declínio do aproveitamento econômico dessa vegetação na área, ela foi sendo gradativamente substituída por vegetação nativa, e hoje há poucas representantes (SÃO PAULO (município), 2001b).

Como já foi colocado, é na região de Evangelista que localizam-se os principais elementos naturais da APA, como a enorme Cachoeira do Capivari, com cerca de $40 \mathrm{~m}$ de altura, e que possui uma visão privilegiada do mar a partir de seu topo.

É também nessa região que ocorre a confluência dos rios Capivari e Monos, que dão nome à APA, e possui em seu curso diversos pontos utilizados por acampistas, e propícios para prática de esportes de aventura, além da exuberante Mata Atlântica ainda preservada. Esses elementos citados e outros existentes coloca a região de Evangelista de Souza como a de maior potencial ecoturístico para a APA.

Os personagens

A região de Evangelista de Souza, no ano de criação de APA, era muito frequentada por acampistas, grande parte deles provenientes da própria zona sul. Possuiam um perfil 
bastante parecido, sempre levando um violão, barraca e o famoso "miojo" - comida de rápido preparo. Buscavam paz, contato com a natureza e isolamento urbano. Para eles, “o Evangelista é maravilhoso!" Os mais antigos disseram em nossa entrevista (em 2001) que "não é mais como antes, está tudo destruído e sujo", mas sempre voltavam para vê-lo.

Outros personagens peculiares na região são os moradores, Sr. Elias (51 anos - em 2001) nascido no sítio que mora, próximo ao ribeirão dos Monos, e vive com seu irmão de 75 anos (em 2001), ambos solteiros. Cultivava algumas hortaliças para subsistência e criava alguns animais, recebia uma aposentadoria da SABESP por ter prestado serviços de medição do nível do Monos, seu irmão cuidava de alguns sítio vizinhos e recebia por isto. Eles sentiam Evangelista como o único lugar possível para morar, não o deixariam para viver na cidade.

Já na Estação Evangelista de Souza, ao se fazer a mesma pergunta à Dona Judite, moradora e proprietária de um pequeno e único comércio na estação, ela respondeu que é "um lugar como outro qualquer". Judite é esposa de Toninho, personagem muito conhecido dos acampistas, pelo seu comércio que "troca de tudo", lá era possível trocar macarrão por biscoitos, arroz por refrigerante, e tornava-se parada obrigatória para quem estáva retornando do acampamento para casa e queria se livrar de alguns pesinhos a mais da mochila, além de fazer o último lanche em Evangelista, apreciando os trens que partem para o porto e que chegam dele, muitos trazendo passageiros pouco bem-vindos pelos fiscais de trens, que logo que os avistavam partiam para a perseguição.

Toninho relembra os tempos dos trens de passageiros que desciam e subiam a serra: "naquele tempo era bom, sempre tinha gente pra comprar coisa aqui, agora nem os meninos que acampam tem mais, os fiscais da ferrovia expulsam um bocado deles", se referindo aos fiscais ferroviários da então companhia FERROBAN, que não permiti-am que ninguém circulasse pelas linhas dos trens, e com isso barravam a passagem de muitos acampistas, estes que tinham como principal caminho a estrada de ferro.

Atualmente a região de Evangelista de Souza possui rara presença de acampistas, e grande parte do patrimônio da estação e da pequena usina hidrelétrica foram depredados.

\section{Núcleo Curucutu do Parque Estadual da Serra do Mar}


As áreas naturais preservadas ou sob proteção ambiental legal na APA, apresentam muitas características singulares diversas e uma particularidade comum aos fragmentos encontrados, eles representam os remanescentes mais importantes da vegetação e da paisagem natural local, conservando a forma original daquela paisagem.

O Núcleo Curucutu do Parque Estadual da Serra do Mar (PESM) tem sua sede localizada na latitude $23 \square 59^{\text {ee }} 06$ " S e longitude 46044"36" O, no limite sul do município de São Paulo e divisa com o de Itanhaém, onde se encontram as estruturas básicas de funcionamento da unidade administrativa e as demais atividades (SÃO PAULO (estado), 1998). Sua área é de $26.542,95$ ha. Distribuídos nos seguintes municípios: São Paulo - 9,45 $\%, 5.506,97$ ha; Juquitiba - 11,08 \% , 2.941,22 ha; Itanhaém - 79,47 \%, 21.094,46 ha.

Apesar da parte localizada em São Paulo não ser nem 10\% da área total do núcleo representam uma zona muito importante, pois se localiza na área de amortecimento da expansão urbana da cidade, isto traz uma constante tensão socioambiental e fundiária, tratase de uma região muito atípica do município.

A sua posição geográfica é estratégica na proteção de muitos ecossistemas particulares da região e de preservação das ultimas áreas rurais remanescentes da Zona Sul do município, de grande importância, pois se tratam das imediações da área de preservação do PESM.

O PESM foi criado pelo Decreto Estadual n 10.251, de 30 Ago. 1977. O Decreto Estadual n 13.313, de 06 Mar. 1979 incorporou a área de antiga Reserva Estadual do Curucutu ao parque, usada até então para extração de madeira e produção de carvão pelo estado. Além dela, os núcleos Santa Virgínia e Picinguaba também foram integrados ao parque por meio deste decreto (ibid.).

O Serra do Mar é o maior parque estadual paulista, com 315.390 ha, abrangendo uma longa extensão de áreas de Mata Atlântica nas encostas da Serra do Mar e no Planalto Atlântico, envolvendo vários municípios, desde Ubatuba (no litoral norte) até Peruíbe e Pedro de Toledo (no litoral sul) e estendendo-se ao Planalto Paulistano junto à Metrópole Paulista. Abriga nascentes de importantes bacias hidrográficas do estado, como as do Paraíba do Sul, Paraíbuna, Tietê-Pinheiros e Ribeira de Iguape (SÃO PAULO (estado), 2000).

O PESM também é tombado pelo CONDEPHAAT como Área Natural, através da resolução SCn40, de 06/06/1985. Em 1991 tornou-se Reserva Mundial da Biosfera pelo programa "O homem e a biosfera" da Unesco, e patrimônio mundial ambiental da humanidade (SÃO PAULO (estado), 1998). 
A localidade do Núcleo Curucutu e a área onde se encontra a sede alta tem origem em 1958 na compra da Faz. Curucutu, produtora de carvão, que foi desativada e adquirida pelo Estado de São Paulo por meio do Dec. Estadual no 36.544/60, com a área de 12.029 ha. Foi transformado em Reserva Florestal (Secção de Reserva da Capital - Serviço Florestal de Estado) com objetivo de recuperação florestal, vale lembrar que o modelo de utilizado era o de reflorestamento com Pinus elliopti. Em 1963 iniciou-se este cultivo com o plantio de 63.000 mudas, o que transformou a paisagem local, com forte descaracterização da paisagem natural. No período de 1977 a 1979 foi incorporada ao PESM, desde então ficou sob administração do Instituto Florestal da Secretaria Estadual do Meio Ambiente (IFSMA $)^{8}$. Em 2001 - ano de criação da APA - o núcleo não contava com uma estrutura minimamente qualificada para atender as necessidades básicas de proteção (ibid.).

\section{Caracterização do Núcleo Curucutu}

O núcleo conta com a presença da Mata Atlântica, representada pela Floresta Ombrófila nas formações densa (montana e alto montana) e nebulares, que se encontram distribuídas pelas colinas de topos arredondados e suaves declives das vertentes, dentro dos limites da APA. Nestas formações há rica presença de bromélias, orquídeas, samambaias e aráceas, bem como onça-parda e a coruja-símbolo do Parque. No Núcleo podemos encontrar, também, campos naturais, alto-montanos de vastas extensões, também contém áreas de pinus, introduzidos há algumas décadas. Conta com uma infraestrutura básica de alojamento, com quartos, banheiros e uma cozinha. Existem, ainda, duas casas onde moram os funcionários do Parque. Próximo ao alojamento há um mirante, de onde se vê o mar, dependendo das condições climáticas, e aonde se chega por uma trilha, em bom estado (SÃO PAULO (estado), 2006).

O Núcleo recebe, eventualmente, estudantes e pesquisadores. Seu isolamento geográfico é acentuado pelo difícil acesso por estradas de terra. Assim, o Núcleo Curucutu é o ponto mais isolado em relação aos demais pontos dentro da APA e mesmo em relação ao posto de saúde mais próximo.

O plano gestor do PESM em 2001

O Projeto de Preservação da Mata Atlântica (PPMA), financiado à Secretaria Estadual do Meio Ambiente do Governo do Estado pelo Governo da Alemanha (banco Kreditanstalt für Wiederaufbau - KfW), tratava-se de um extenso projeto de proteção e gerenciamento do

\footnotetext{
${ }^{8}$ Atualmente é gerido pela Fundação Florestal de São Paulo (FF-SP), órgão do governo do estado.
} 
PESM, o investimento era da ordem de U\$ 35 milhões, sendo 56\% doados pelo KfW, e 44\% do Governo de Estado (SÃO PAULO (estado), 1998).

A verba foi destinada de acordo com o PPMA, resumidamente em duas principais categorias: A. mais de 50\% dos recursos para a fiscalização e monitoramento; e B. o restante para a elaboração dos planos de gestão e manejo, e para o desenvolvimento dos núcleos distribuídos pelo parque.

Desta distribuição passou-se à criação dos Planos de Gestão dos Núcleos para formar um Plano de Manejo do PESM, os núcleos a serem desenvolvidos seriam Picinguaba, Cubatão, Santa Virgínia, Caraguatatuba, além dos parques Ilha do Cardoso e Ilha Bela e as estações de Bananal e Chauá.

No entanto devido a extensão do PESM, 1.713.723,03 ha, em 39 municipalidades, e em uma área continua, as diretrizes iniciais foram mudadas. Isto ocorreu em um contexto político meio conturbado, e a postura do Estado (principalmente dos Secretários de Meio Ambiente que passarem pelo governo), não contemplou a divisão original dos recursos, das atividades e dos núcleos.

Em meio a estas alterações novos núcleos foram criados, mas não foram desenvolvidos, verbas foram remanejadas dentro do projeto durante o surgimento dos novos núcleos, porém a aplicação dos mesmos não se realizou.

No Núcleo Curucutu os efeitos foram diretos, o mais relevante foi no desenvolvimento do plano de gestão, sendo elaborado por anos, mas só efetivamente trabalhado a partir de 2000. O trabalho teve verbas escassas e um quadro técnico reduzido, e contou com o apoio de estagiários voluntários e teses de mestrado e doutorado que contribuíram na sua elaboração.

O plano de gestão ou manejo foi elaborado por uma equipe técnica multidisciplinar composta por seis pessoas, a escassez de materiais foi muitas vezes suprida por levantamentos e trabalhos encomendados a terceiros, revelando as condições do estado, principalmente no quadro humano dos trabalhos.

No ano de criação da APA, a falta do plano de gestão (ou manejo) tornou mais delicada a situação do núcleo e da área natural a proteger na APA. Uma síntese das tensões da situação do núcleo em 2001 pôde revelar um panorama mais simples da trama socioambiental encontrada nesta unidade. O plano gestor do núcleo estava em fase de elaboração e tinha previsão de entrega para o final de 2002. Entretanto vinha sendo elaborado há alguns anos por uma equipe interdisciplinar do Instituto Florestal coordenada 
pelo então diretor do núcleo Mauricio Alonso. Em 2006 o Plano foi aprovado pelo CONSEMA (Conselho Estadual de Meio Ambiente) (cf. SÃO PAULO (estado), 2006).

Em entrevista concedida em 23 Nov. 2001, o então diretor Maurício afirmou que a maior preocupação do núcleo era a relação com a vizinhança, "a preservação do núcleo depende do entorno, pois as condições presentes [2001] dele não comporta grande acesso ao público devido a carente infra, que tornou-se a principal diretriz".

Por isso, conjuntamente aos estudos do plano de manejo, foi elaborado o projeto para a implementação de equipamentos e estruturas de apoio a visita e a pesquisa. Maurício acreditava que "a lentidão do processo foi ocasionada quase que totalmente pela falta de novos quadros técnicos e de apoio para se desenvolverem as atividades do projeto do plano gestor ou de manejo".

\section{As necessidades do Núcleo}

As principais necessidades do núcleo em 2001 estavam relacionadas a elaboração do plano de manejo, mas a preocupação mais importante era em relação a preservação de seus remanescentes naturais e da delimitação da fronteira do PESM Núcleo Curucutu devido aos conflitos fundiários e as pressões por invasão.

A maior preocupação daquela gestão era a de se preservar o local, dados os aspectos singulares objetos de preservação. A opção do diretor foi de manter o lugar fechado até que se promulgasse o plano, mas independente disso ele já desenvolvia, em parceria com pesquisadores e instituições, estudos para roteiros de visita, mapeamento de trilhas, levantamentos de capacidade de uso, de fauna e flora, projetos para construção da base de pesquisadores e outros elementos necessários para a ocupação do núcleo. A ideia do diretor era adequar todo o núcleo e preparar o entorno para assim depois abri-lo para o uso público. Estes estudos também contribuíram no desenvolvimento dos estudos do plano de manejo.

Outro aspecto extremamente relevante no quadro de necessidades do núcleo em 2001 era a falta de recursos humanos, a distancia e o difícil acesso ao centro operacional tornavam o núcleo deficiente em vigilância, manutenção, informação e outras atividades dependentes de pessoas habilitadas. Na época apenas dois funcionários trabalhavam: um caseiro pago pelo estado e um funcionário disponibilizado pela prefeitura de Itanháem.

A tensão em torno do núcleo e de sua vizinhança era presente na dissimulada política do PESM, pois não havia diálogo entre as partes competentes e de jurisdição em relação aos planos de uso. Por um lado, através da SVMA, representando a Prefeitura de São Paulo, e do outro, o Instituto Florestal, através da direção do Núcleo, representando o estado, não 
haviam obtido sucesso na forma de atuação convergente e integradora necessária para ambos os planos de gestão, da APA Capivari-Monos e do Núcleo Cururutu. Atualmente os conflitos diminuíram, e muitas parcerias ocorreram entre as esferas, e os planos de manejo de ambas unidades de conservação foram concluídos contando com a participação dos dois entes.

\section{Vila de Eng. ${ }^{\circ}$ Marsilac}

Bairro rural da cidade, foi fundado junto com a construção do ramal Santos-Mairinque da EFS, na década de 1940, a partir da parada ferroviária de mesmo nome, apesar de possuir moradores desde a década de 1830, quando ainda pertencia ao antigo município de Santo Amaro, atualmente bairro de São Paulo. Marsilac é o bairro mais meridional do município de São Paulo, distando $40 \mathrm{~km}$ ao sul em linha reta do centro (Praça da Sé) e apenas $23 \mathrm{~km}$, a sudeste, do litoral de Mongaguá. Da região limítrofe deste distrito, junto às escarpas da Serra do Mar, ainda no município de São Paulo, já é possível avistar o mar.

Engenheiro Marsilac abriga em sua área uma das mais conhecidas corredeiras do rio Capivari, disputada por muita gente em dias quentes. Antes da criação da APA não era devidamente explorada turisticamente, apresentando uma visita desordenada.

A visão que se tem do bairro é a de uma pequena vila interiorana com casario de estilo ferroviário e construções térreas alinhadas ao passeio público, que parece não mudar de tamanho, porém em seus arredores já é possível presenciar alguns loteamentos irregulares surgindo na paisagem.

Os moradores antigos não estão muito entusiasmados com o aparecimento de novos vizinhos que, segundo eles, só trouxe criminalidade, sujeira, derrubada de mata e rios sujos.

A líder da sociedade de bairro de Marsilac, dona Maria Lúcia, foi uma das motivadoras no processo de criação da APA, ela contou que já foi ameaçada algumas vezes de morte na luta por esta causa.

Marsilac está localizado praticamente na área central da APA Capivari-Monos, possuindo apenas 6 logradouros e uma pequena praça, onde faz ponto final a última linha de ônibus coletivo com destino à cidade de São Paulo. Os moradores nascidos no local são bastante consciente quanto a necessidade de preservação natural.

É tido como referência para a população rural para suas necessidades básicas de consumo. Apesar de sua rua principal contar com poucos estabelecimentos comerciais (5 ou 
6 em 2001). É também local de residência dos proprietários rurais que têm ainda alguma produção agrícola (agricultura orgânica ou convencional, caprinocultura, silvicultura etc.).

Com relação às diretrizes da APA Capivari-Monos, o bairro apresenta os seguintes aspectos: do ponto de vista da paisagem é ainda o local que melhor conserva as condições ambientais, principalmente na cobertura florestal que circunda o bairro; como aspecto negativo é a falta de saneamento básico, principalmente rede coletora de esgoto e resíduos domésticos, que ficam acumulados nas valas de drenagem pluvial.

Em função da pequena população do local, os problemas acima levantados podem ser solucionados dentro dos objetivos estabelecidos pela APA. A expansão do bairro, que será inevitável, deverá ser estabelecida com muito critério no plano de zoneamento para evitar uma futura degradação socioambiental.

\section{Aldeia Guarani Tenondé Porã}

Tenondé Porã, que significa "luz da esperança" ou "futuro bonito", é o nome Guarani da aldeia da Barragem, antiga Morro da Saudade, como é conhecida pelos não-índios. Os índios que aí vivem são Mbiá (Mbüá ou Mbyá), subgrupo Guarani que diferencia-se dos outros dois, Kayová e Ñandéva, através do dialeto e também de alguns aspectos da cultura material e não material (SCHADEN, 1974).

A aldeia começou a ser formada na década de 1960 e foi homologada pela FUNAI (Fundação Nacional do Índio) em 1987. Em 2001 era composta por 120 famílias (aproximadamente 650 hab.), configurando o maior agrupamento do Estado de S. Paulo. Ocupavam 26 ha de terra, e dentre suas atividades estava a agricultura (especialmente mandioca, batata e banana), o comércio do artesanato e pesca de forma não sistemática.

Seus integrantes não são descendentes de nenhum antigo aldeamento paulista, como poderia se supor. São provenientes de uma das numerosas correntes migratórias vindas do Sul e do Oeste em direção ao território paulista, às quais a etnia se submete desde o início do século. No caso em estudo, a procedência é Palmeirinha, no Paraná, sendo que a este grupo juntaram-se também famílias vindas do litoral (AZANHA \& LADEIRA, 1988).

Schaden (1974) afirma que "o motivo das jornadas é o Yvý opá (Yvý-jú), o fim do mundo, profetizado pelos chefes religiosos da tribo", que guia o grupo em direção a "Terra sem Males", para qual o litoral seria um caminho. 
Em relação a infraestrutura em 2001 a aldeia estava equipada de posto de saúde, escola, caixas d’água e rede elétrica, além de contar com linha de ônibus e vias pavimentadas próximas à sua entrada.

\section{A fixação dos Guarani na terra}

Como apresentado, as aldeias Guarani da APA não são resultantes da política colonial de aldeamentos que aglutinou grupos indígenas do atual território do Estado de São Paulo, como os Tamoios (litoral norte paulista e vale do Paraíba), Guaianazes e Guarulhos (planalto paulista) ou os Muiramoris (PETRONE, 1995).

Entre os Guarani o nomadismo sempre configurou-se como uma das principais características. Sem nunca fixar residência, vivendo na mata, mantinham um estreito contato com a natureza (TANGERINO, 1996). Devido a esta característica, houve diversos problemas relativos à demarcação de terras. Basta reparar no famoso argumento mais utilizado pelos grileiros: "nós chegamos aqui antes dos índios"; que foi legitimado em diversos processos de expulsão contra os Guarani. Este pode ser caracterizado como um dos motivos pelo qual as tribos começaram a fixar-se em aldeamentos perenes.

As primeiras aldeias Guarani em São Paulo a se fixarem nos tempos atuais datam do início do séc. XIX, sendo que a ocupação mais expressiva só ocorre em meados do XX, incluído neste movimento a aldeia da Barragem (CHEROBIM, 1986).

\section{A cultura Guarani}

Um dos principais aspectos da cultura Guarani é sua grande religiosidade. Na forma da sacralização e ritualização do mundo, é, certamente, um dos elementos que vai particularizar sua relação com o espaço em que vive. No centro de seus aldeamentos encontra-se a função religiosa, materializando a posição central que este aspecto ocupa em sua vida (SCHADEN, 1974; AZANHA \& LADEIRA, 1988; BARBOSA, 1994). Paralelamente, estes espaços acabam também funcionando como palco para a vida social ou para práticas de administração.

A noção de propriedade da terra também é influenciada por esta concepção: para eles, a terra não tem dono, ou melhor, o único dono é Ñanderú (Deus). É claro que hoje em dia, devido ao grau de aculturação, a noção de propriedade privada já começa a ser entendida, ao menos pelos líderes, que são mesmo impelidos a respeitar a lei dos brancos (BARBOSA, op. cit.). Esta noção básica do sistema capitalista gera uma série de desdobramentos no que diz respeito à relação com a terra, que diferencia-se exponencialmente da relação primordial encontrada entre os povos tradicionais. 
Mesmo o processo de aculturação não sendo o foco de análise deste trabalho, é importante entender algumas categorias da relação dos indígenas com o espaço em que vivem, para que seja possível compreender a forma pela qual algumas delas ainda persiste, mesmo que de forma residual, particularizando sua relação com o solo.

Originalmente viviam um comunismo primitivo, "uma forma de produção baseada numa estrutura comunitária praticamente autossuficiente" (OLIVEIRA, 1995). Desta forma, tirando do solo seu sustento, o contato com a natureza era estreito. No caso dos Guarani, esta relação parece ser ainda mais forte, graças a dois aspectos adicionais: 1. Quando não em migração, procuravam fixar-se no meio da floresta, afastados de outras civilizações; 2. Profunda religiosidade, que manifesta-se também em relação à natureza.

Com a aproximação da civilização Ocidental, o processo de aculturação entra inevitavelmente em marcha, mas isto não impede que as características mais marcantes de uma sociedade exerçam uma força contrária a estas pressões externas. Isto é possível observar na paisagem interna das aldeias ou na distribuição destas no território.

A natureza nômade dos Guarani, por exemplo, pode ser diagnosticada na forma pela qual configuram as aldeias. Quando assim organizados e em condições favoráveis, sua inclinação é a de ocupar grandes porções de terra, com delimitações imprecisas.

Por estas particularidades, a paisagem configurada pelo assentamento da aldeia diferencia-se de todas outras ocupações na APA. Assemelham-se aos bairros rurais, porém os espaços livres e ajardinados encontram-se espalhados por toda reserva, sendo que as construções arranjam-se em meio à natureza.

\section{CONCLUSÃO}

Todas as perguntas que o presente artigo buscou responder - apresentadas na introdução - na verdade, correspondem a própria conclusão do trabalho, já que o objetivo foi aplicar a conceituação de algumas teorias geográficas da paisagem. Neste sentido, elas foram plenamente suficientes para a análise geográfica da paisagem delimitada pela APA Capivari Monos, pois, caso contrário, estas colocações não teriam sido geridas.

Ressalta-se os conflitos de interesse relativos ao uso e ocupação do solo, mostrando que os elementos que compõe as paisagens são forças atuantes e em constante mudança. 
Dos resultados obtidos através da análise das entrevistas coletadas em campo no ano de criação da APA, e que inserem-se na metodologia da percepção ambiental, obtive-se as seguintes conclusões:

1. No geral, os elementos naturais como as matas (reflorestadas, secundárias ou primárias) e cachoeiras atraem mais a atenção como elemento da paisagem local e também como pontos de referência. Isto principalmente quando se refere aos moradores mais antigos e visitantes que vêm ao local com interesse turístico. Os moradores de loteamentos recentes têm pouca integração ainda com o local, inclusive tendo dificuldade de descrever visualmente o lugar em que se encontram.

2. Como elementos cognitivos há uma grande rejeição de parte da população da APA aos loteamentos clandestinos, mas esta é uma realidade local consolidada que deve ser considerada nas políticas da unidade. Principalmente no caso de Vargem Grande, onde o fato de estar sobre uma bacia sedimentar semi-confinada na cratera e estar sujeita ao despejo esgoto de mais de 35.000 habitantes em fossas negras, isto deverá agravar muito as condições do lençol freático em curto prazo, pois as areias quartzosas de baixa retenção hídrica, logo estarão saturadas pelo fato de estar numa bacia fechada com um único estravasor, que é o ribeirão Vermelho. O incremento de esgoto desta população já deve estar maior que a vazão natural do rio.

3. Outro fato relevante foi o desconhecimento da população sobre a criação da APA, o significado do ecoturismo, ou ainda a existência da cratera, que deverá servir de base para direcionamento da educação ambiental com o plano de manejo.

Assim, este artigo pretendeu contribuir ao entendimento e difusão do conhecimento sobre esta que é uma região ao mesmo tempo tão deslumbrante e desconhecida da maior cidade do hemisfério sul, inclusive por seus habitantes.

\section{BIBLIOGRAFIA}

AZANHA, G \& LADEIRA, M I. Os índios da Serra do Mar: a presença Mbyá-Guarani em São Paulo. São Paulo: CTI \& Nova Stella Ed., 1988.

BARBOSA. C G A. Trazidos... por Tupã: a luta pelo território Guarani em São Paulo. São Paulo: Mestrado/FFLCH/USP, 1994.

BELLENZANI. M L R. A APA Municipal do Capivari-Monos como uma estratégia de proteção aos mananciais da Região Metropolitana de São Paulo. São Paulo: Mestrado/IGc/USP, 2000. . (coord.). Plano de Manejo: APA Capivari-Monos. S.P.: SVMA, 2011.

BERTRAND, G. Paisagem e Geografia Física Global. São Paulo: Cad. de Ciências da Terra, 1971. BRUNO, E. S. São Paulo, Terra e Povo. São Paulo: Ed. Globo, 1967. 
CHEROBIM, M. Os índios guarani do litoral de Estado de São Paulo: análise antropológica de uma situação de contato. Dissertação Mestrado em Ciências Sociais. S. Paulo: FFLCH-USP, 1986.

DEL RIO, V. Cidade da mente, cidade real: percepção ambiental e revitalização da área portuária do RJ. In: DEL RIO, V.; OLIVEIRA, L. (org.). Percepção ambiental: a experiência brasileira. São Paulo: Studio Nobel/UFSCar, 1999.

ELETROPAULO - Eletricidade de São Paulo. Estudos de Impacto Ambiental (EIA) e Relatório de Impacto Ambiental (RIMA) da remodelação do sangradouro Preto-Monos. São Paulo: ELETROPAULO, 1995.

LEFEBVRE, H. Espacio y Política. Barcelona: [s.e], 1976.

MARCONDES, M. J. de A. Cidade e natureza: proteção dos mananciais e exclusão social. São Paulo: Studio Nobel, Edusp, 1999.

MARICATO, E. Política Urbana, exclusão social e violência. In. Caramelo, n 8. São Paulo: FAUUSP, 1995.

McDOWELL, L. A transformação da geografia cultural. In: Gregory, et. ali. Geografia humana: sociedade, espaço e ciência social. Rio de Janeiro: Jorge Zahar, 1996. 310p.

MONTEIRO, C. A. F. Geossistemas: a história de uma procura. S.P.: Contexto, 2000.

OLIVEIRA, A. U. Modo capitalista de reprodução e Agricultura. São Paulo: Ática, 1995.

PETRONE, P. Aldeamentos Paulistas. São Paulo: EDUSP, 1995.

SANTOS, Rodrigo Martins dos. Geografia Humana de Colônia Paulista e Ilha do Bororé (bairros de Parelheiros e Grajaú, cidade de São Paulo). São Paulo: SPPA, 2005.

SÃO PAULO (estado). Uma nova política de Mananciais: Diretrizes e Normas para a Proteção e Recuperação das Bacias Hidrográficas dos Manaciais de Interesse Regional do Estado de São Paulo. São Paulo: SMA, 1997.

. Plano de manejo das unidades de conservação: Parque Estadual da Serra do Mar. Plano de Gestão Ambiental-Fase 1. São Paulo: SMA-SP, 1998.

. Atlas das unidades de conservação ambiental do estado de São Paulo: parte I, litoral. São Paulo: SMA-SP, 2000.

. Plano de Manejo do Parque Estadual da Serra do Mar. S. P.: IF, 2006.

SÃO PAULO (município). Diagnóstico de Estradas e Vias de circulação da APA CapivariMonos. São Paulo: SVMA, 2001a.

. Proposta de ecoturismo para a região de Evangelista de Souza na APA

CapivariMonos. São Paulo: SVMA, 2001 b.

. Município em Mapas - índices sociais. São Paulo, SEMPLA, 2006.

SCHADEN, E. Aspectos fundamentais da cultura Guarani. Livre-Docência/FFLCH/USP. 3. ${ }^{a}$ ed. São Paulo: EdUSP, 1974.

SEABRA, O. C. de L. \& SPÖRL, A. A lei de proteção aos mananciais versus a prática social de ocupação da Bacia do Guarapiranga. In Revista do Depto. de Geografia n. ${ }^{\circ}$ 11. FFLCH/USP. São Paulo: Humanitas, 1997.

SPOSATI, A., coord. Mapa da exclusão/inclusão social da Cidade de São Paulo. São Paulo, EDUC, 1996.

TANGERINO, C. C. Revelações sobre a terra: a memória viva dos Guarani. UFES, Vitória, 1996.

VICTORINO, V. I. P. Os desafios sócias da questão ambiental: proteção das águas e luta por moradia na cratera de Colônia. São Paulo: Puc-SP, 1996. 